\title{
Is there any difference in local time variation in ionospheric F2-layer disturbances between earthquake-induced and Q-disturbance events?
}

\author{
T. Xu ${ }^{1}$, Y. L. Hu ${ }^{1}$, F. F. Wang ${ }^{1}$, Z. Chen ${ }^{2}$, and J. Wu ${ }^{1}$ \\ ${ }^{1}$ National Key Laboratory of Electromagnetic Environment, China Research \\ Institute of Radiowave Propagation (CRIRP), 266107 Qingdao, China \\ ${ }^{2}$ Institute of Earthquake Science, China Earthquake Administration,100036 Beijing, China \\ Correspondence to: T. Xu (xutong1104@126.com)
}

Received: 10 September 2014 - Revised: 27 April 2015 - Accepted: 1 May 2015 - Published: 3 June 2015

\begin{abstract}
Ionospheric anomalies before earthquakes have become the subject of one of the most intensive studies in the area of ionospheric variation. The ionosphere has a large class of disturbances under quiet geomagnetic conditions, i.e., quiet time disturbances (Q disturbances). Hence, the characteristics of seismo-ionospheric anomalies obtained by statistical analysis should be compared with those of Qdisturbance events. Using the data of $f o \mathrm{~F} 2$ (F2-layer critical frequency) during the whole interval of 1978-2008 ( 3 solar cycles), the local time (LT) variation in Q disturbances is investigated. The results showed that a well-pronounced nighttime peak took place for positive disturbances induced by Q-disturbance events, while positive disturbances related to earthquakes predominately occurred in the daytime, especially in the afternoon LT sector. This remarkable difference in local time variation in $f o \mathrm{~F} 2$ between the earthquaketriggered and Q-disturbance events is of great significance for the identification of ionospheric precursors.
\end{abstract}

Keywords. Ionosphere (ionospheric irregularities)

\section{Introduction}

The ionospheric effects produced by seismic activity have attracted geophysicists' attention for many years, due to the urgent need for the timely prediction of large earthquakes that cause massive destruction. The ionospheric anomalies before large earthquakes occur are investigated widely by many geophysicists, and a considerable number of papers have reported on deviations in the daily values of the F2-layer crit- ical frequency $(f o \mathrm{~F} 2)$, total electron content (TEC), and in situ electron density in the days prior to the main shock $(\mathrm{Pu}-$ linets, 1998a; Dabas et al., 2007; Zhao et al, 2008; Sharma et al., 2010; Liu et al., 2011; Li and Parrot, 2013).

To obtain more convincing results, statistical analysis of ionospheric change before earthquakes is effective and is also needed. Liu et al. (2006) investigated the relationship between variations in $f o \mathrm{~F} 2$ and 184 earthquakes with magnitude $M>5.0$ during 1994-1999 in the Taiwan area; the investigation showed that the ionospheric disturbance in $f o \mathrm{~F} 2$ significantly occurred during the afternoon period, 12:0018:00 LT (local time), during the 5 days before the earthquakes. A total of $736 M>6.0$ earthquakes worldwide during 2002-2010 were statically studied using TEC data, and the feature of LT variation in ionospheric anomalies was confirmed (Le et al., 2011). Moreover, empirical dependencies of the seismo-ionospheric disturbances relating the earthquake magnitude and the epicenter distance were discussed by means of statistical analysis (Perrone et al., 2010; Saradjian and Akhoondzadeh, 2011). However, the existence of the seismo-ionospheric precursors is still an open issue because of high ionospheric variability and the influence of solar activity. Although the definition of quiet conditions for the ionosphere is quite difficult to obtain, generally the influence of geomagnetic disturbances originating from solar activity could be eliminated by setting thresholds of geomagnetic indices. Recently, a cross-wavelet analysis was proposed by $\mathrm{He}$ et al. (2014), which displayed a capability of detecting the ionospheric anomalies triggered by earthquakes in unquiet solar-terrestrial environments. Nevertheless, the ionosphere itself has significant day-to-day variability and displays os- 

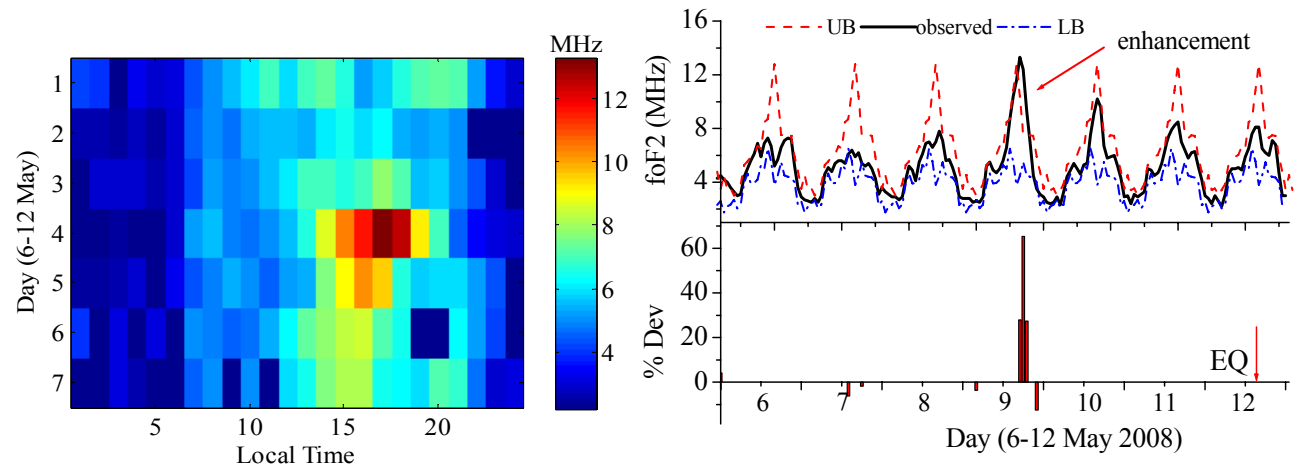

Figure 1. Significant enhancement in $f o F 2$ at Chongqing station (about $300 \mathrm{~km}$ east of the epicenter) 3 days before the onset of the 2008 Wenchuan earthquake (modified from Xu et al., 2010a, b). UB and LB were calculated according to the method proposed by Liu et al. (2004).

cillation over a wide range of timescales due to solar irradiation variability, meteorological influences, and solar wind energy input. Even for geomagnetic quiet days, day-to-day variability is of great importance. We refer to these events as " $Q$ disturbances" (Mikhailov et al., 2004). Forbes et al. (2000) showed that under quiet conditions $(\mathrm{Kp}<1)$, the standard deviation of the ionospheric peak electron density $(N m \mathrm{~F} 2)$ was up to $35 \%$. Mikhailov et al. $(2004,2007)$ also showed that Q disturbances of $N m \mathrm{~F} 2$ could differ by more than $40 \%$ from its mean values.

The accurate specification of the difference between earthquake-induced and Q-disturbance events constitutes the main challenge for improved discrimination of seismoionospheric precursors. Hence comparative analysis should be made, to which seldom attention has been paid to date. The object of this paper is to study the ionospheric variation in LT due to earthquakes, and compare it with that of Q-disturbance events; some interesting results are achieved. The data of $f o \mathrm{~F} 2$, within a 15-day period before the chosen earthquakes during the interval 1966-2008 in China, are used to check ionospheric anomalies, and $f o \mathrm{~F} 2$ data covering about three solar cycles, 1978-2008, are used to investigate $\mathrm{LT}$ variation in $\mathrm{Q}$ disturbances.

\section{Local time variation in the ionosphere related to earthquakes}

Much effort has been devoted to finding temporal variation in ionosphere disturbances due to earthquakes. Statistical analysis has shown that the earthquake-induced ionospheric anomalies versus LT are most frequent in the afternoon LT sector, approximately 12:00-18:00 LT (Pulinets et al., 1998b; Liu et al., 2006; Sharma et al., 2010). Pulinets et al. (2003) showed that the ionospheric deviations in $f o \mathrm{~F} 2$ were positive or negative depending on the position of the ionosonde in relation to the anomaly formed in the ionosphere. However, Le et al. (2011) found that the occurrence rate of abnormal increase was much higher than that of ab- normal decrease. Investigations of recent large earthquakes support such a conclusion to some extent. Figure 1 demonstrates the pronounced enhancement in $f o \mathrm{~F} 2$ in the afternoon LT sector at Chongqing station 3 days prior to the 2008 Wenchuan earthquake, which has been recognized by many authors (e.g., Zhao et al., 2008; Zhou et al., 2009; Xu et al., 2010a, b), and similar to the temporal variation in the ionosphere before the 2010 Haiti earthquake (Pulinets et al., 2010; Liu et al., 2011) and the 2011 Tohoku earthquake (He et al., 2012; Hu et al., 2013).

Although many results demonstrated frequent ionospheric disturbances in the afternoon due to earthquakes, some inconsistent features are observed. e.g., positive deviation lasting $12 \mathrm{~h}$ from 16:00 to 04:00 was observed in Greece (Davidenko, 2013). In addition, Liu et al. (2006) found significant decreases in the afternoon period in Taiwan. Pulinets and Davidenko (2014) claimed that the disturbances might be specific for different seismic zones. Recently, using the method of interquartile range proposed by Liu et al. (2004), we analyzed the ionospheric variations in $f o \mathrm{~F} 2$ before all the 14 large earthquakes with $M \geq 7.0$ listed in Table 1 during the interval 1966-2008 in China (Hu, 2011; Xu et al., 2012a). According to this method, interquartile range was calculated to construct the upper bound (UB) $X+I Q R$ and lower bound (LB) X-IQR for the data estimation, where $\mathrm{X}$ was the median. It is well known that the ionosphere has strong seasonal, annual, and solar cycle variations; hence using a long-term data set to calculate the median is not wise. Here, the median was calculated over 15 days of data. Under the assumption of normal distribution, the expected value of IQR was $1.34 \sigma$. UB and LB were calculated by $\mathrm{X}+1.34 \sigma$ and $\mathrm{X}-1.34 \sigma$. If the $f o \mathrm{~F} 2$ value at this time point was larger than the UB or smaller than LB, it was defined as an abnormal point.

In this section, we will not present ionospheric variations before each of the 14 large earthquakes with $M \geq 7.0$. Because the results available in $\mathrm{Hu}$ (2011) and Xu et al. (2012a) were written in Chinese, we introduce the method of interquartile range (described above), present the key results, 


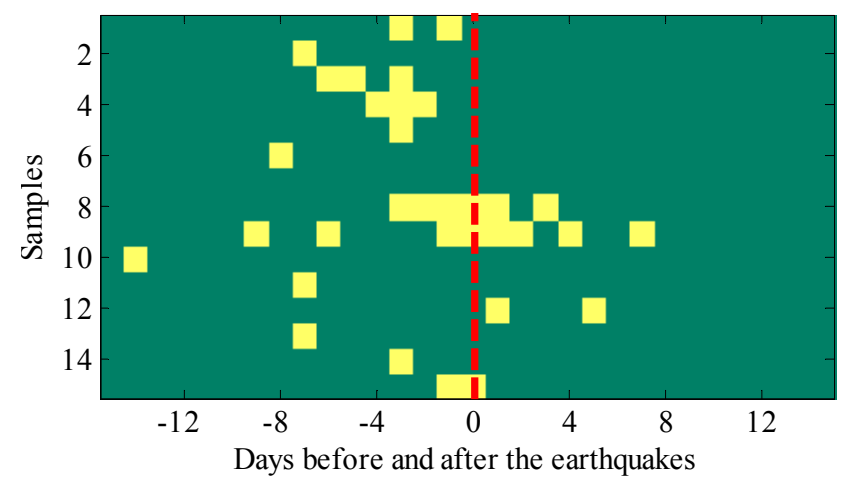

Figure 2. Days of ionospheric disturbances before and after the shocks of 14 large earthquakes with $M \geq 7.0$ during 1966-2008 in China (modified from Hu, 2011, and Xu et al., 2012a).

and give an interesting example of an earthquake event which singles out ionospheric anomalies.

Using the method of interquartile range proposed by Liu et al. (2004), analysis showed that the ionospheric increase predominantly appeared during 11:00-17:00 LT $\sim 7$ days prior to $85.7 \%$ (12) of the 14 earthquakes. Figure 2 shows the days of ionospheric anomalies prior to the main shocks, i.e., a higher occurrence during the several days before earthquakes, which is consistent with the conclusions drawn by many authors (Pulients, 2003; Liu et al., 2004, 2006; Le et al., 2011; etc). However, by analyzing 11 earthquakes in 20032005, Dabas (2007) claimed that the ionospheric anomalies occurred 2 to 25 days prior to the earthquakes. Figure 3 illustrates the occurrence of ionospheric abnormal increase in foF 2 versus $\mathrm{LT}$, from which one can see that though the positive disturbances were sometimes present at nighttime, the disturbances predominately occurred during the afternoon period. Reports of ionospheric anomalies at nighttime are more limited, but some exist (Zakharenkova et al., 2006). This feature of LT variation in $f o \mathrm{~F} 2$ triggered by earthquakes is in line with the conclusions by Pulinets et al. (1998b) and Liu et al. (2006).

Note that geomagnetic activity can give rise to significant ionospheric disturbances. Ionospheric disturbances due to earthquakes need to be distinguished from geomagnetic activity. The ionospheric disturbances before the Songpan earthquake (16 August 1976), listed in Table 1, were chosen as an example which simultaneously considers the effects related to both an earthquake and a geomagnetic storm. Ionospheric variations over Chongqing and Urumuqi (about 400 and $2000 \mathrm{~km}$ away from the epicenter, respectively, shown in Fig. 4) before the main shock are shown in Fig. 5. The preparation area was calculated as $1200 \mathrm{~km}$ according to the Dobrovolsky equation (Dobrovolsky et al., 1976), $r=10^{0.43 \mathrm{M}} \mathrm{km}$, implying that the ionosphere over the Chongqing station might be affected by the earthquake, but not by the latter.

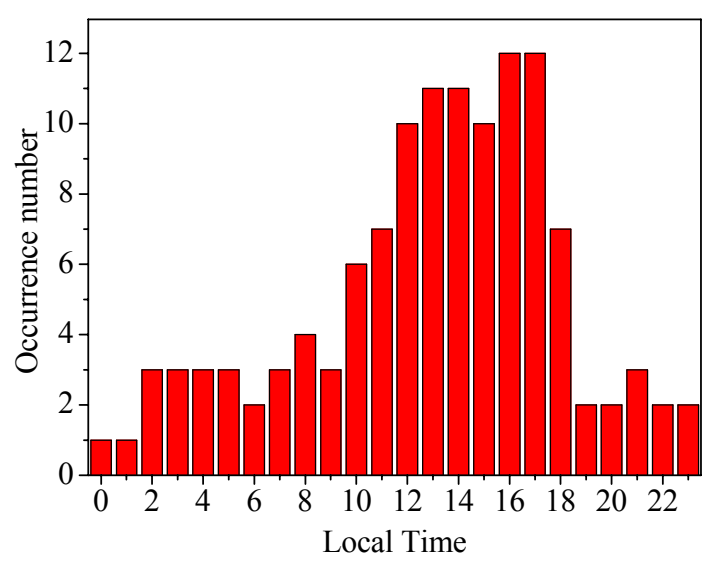

Figure 3. Occurrence number for abnormal increase in $f o \mathrm{~F} 2$ versus local time in the 15 days before the selected earthquakes (modified from $\mathrm{Hu}, 2011$, and $\mathrm{Xu}$ et al., 2012a).

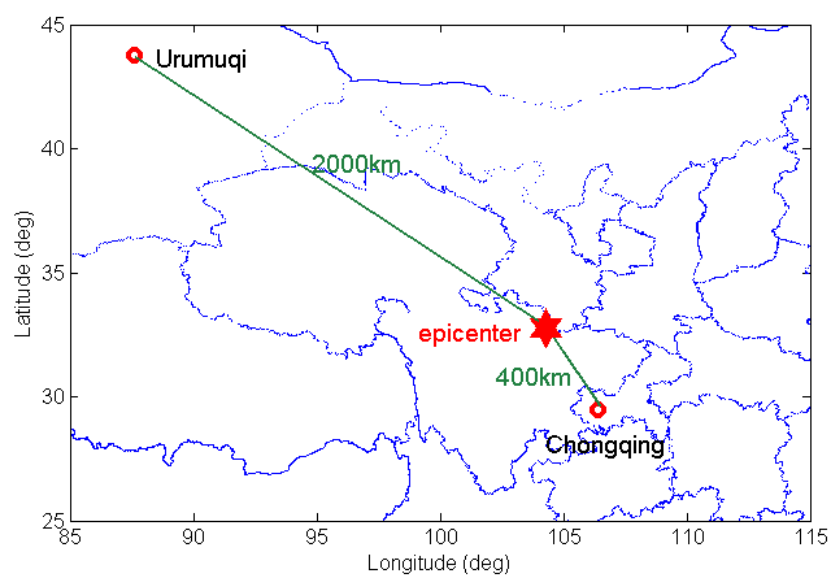

Figure 4. Locations of Chongqing, Urumuqi, and the epicenter of the Songpan earthquake (16 August 1976).

One can see that there was a weak geomagnetic storm before the main shock, marked by a shaded rectangle, with a minimum Dst of $-32 \mathrm{nT}$, and that distinctly positive disturbances occurred during the storm at the two stations. Moreover, remarkable enhancements in $f o \mathrm{~F} 2$ during 15:0017:00 LT (corresponding to day 4 in Fig. 2; it should be pointed out that the day 5 and day 6 values correspond to the ionospheric disturbances over Lhasa station, about $1000 \mathrm{~km}$ from the epicenter, not shown) over Chongqing station, near the epicenter, were observed under quiet geomagnetic conditions, while there was an unobvious disturbance in $f o \mathrm{~F} 2$ over Urumuqi station. The localization is possibly one of the most important signatures related to seismic activity, in contrast to global-scale disturbances triggered by geomagnetic storms (Pulinets et al., 2003; Zhao et al., 2008). This distinct feature was also observed in TEC extracted from global ionospheric maps (GIMs) before the moderate $\mathrm{M}=4.72010$ Chongqing earthquake (with a very shallow depth of $7 \mathrm{~km}$, 
Table 1. List of the earthquakes selected in China (modified from Xu et al., 2012a).

\begin{tabular}{lllccc}
\hline Case study & Date (dd/mm/yyyy) & Longitude (degrees) & Latitude (degrees) & Magnitude $(M)$ & Focal depth $(\mathrm{km})$ \\
\hline Xingtai & $22 / 03 / 1966$ & $114.81^{\circ} \mathrm{E}$ & $37.51^{\circ} \mathrm{N}$ & 7.2 & 9 \\
Liaoning & $04 / 02 / 1975$ & $122.70^{\circ} \mathrm{E}$ & $40.70^{\circ} \mathrm{N}$ & 7.3 & 16 \\
Tangshan & $28 / 07 / 1976$ & $118.00^{\circ} \mathrm{E}$ & $39.40^{\circ} \mathrm{N}$ & 7.2 & 22 \\
Songpan & $16 / 08 / 1976$ & $104.30^{\circ} \mathrm{E}$ & $32.80^{\circ} \mathrm{N}$ & 7.2 & 24 \\
Songpan & $23 / 08 / 1976$ & $104.30^{\circ} \mathrm{E}$ & $32.50^{\circ} \mathrm{N}$ & 7.0 & 23 \\
Qinghai & $26 / 04 / 1990$ & $100.33^{\circ} \mathrm{E}$ & $36.06^{\circ} \mathrm{N}$ & 7.2 & 9 \\
Xinjiang & $14 / 06 / 1990$ & $85.09^{\circ} \mathrm{E}$ & $47.90^{\circ} \mathrm{N}$ & 7.3 & 57 \\
Yunnan & $12 / 07 / 1995$ & $99.16^{\circ} \mathrm{E}$ & $21.96^{\circ} \mathrm{N}$ & 7.0 & 13 \\
Yunnan & $03 / 02 / 1996$ & $100.25^{\circ} \mathrm{E}$ & $27.34^{\circ} \mathrm{N}$ & 7.1 & 10 \\
Kunlun & $19 / 01 / 1996$ & $78.35^{\circ} \mathrm{E}$ & $34.43^{\circ} \mathrm{N}$ & 7.5 & 7.0 \\
Tibet & $08 / 11 / 1997$ & $87.33^{\circ} \mathrm{E}$ & $35.26^{\circ} \mathrm{N}$ & 8.1 & 34 \\
Jilin & $08 / 04 / 1999$ & $130.34^{\circ} \mathrm{E}$ & $43.61^{\circ} \mathrm{N}$ & 3.0 & 578 \\
Kunlun & $14 / 11 / 2001$ & $90.53^{\circ} \mathrm{E}$ & $35.92^{\circ} \mathrm{N}$ & 7.2 & 11 \\
Wenchuan & $12 / 05 / 2008$ & $103.42^{\circ} \mathrm{E}$ & $31.01^{\circ} \mathrm{N}$ & 7.2 & 14 \\
\hline
\end{tabular}

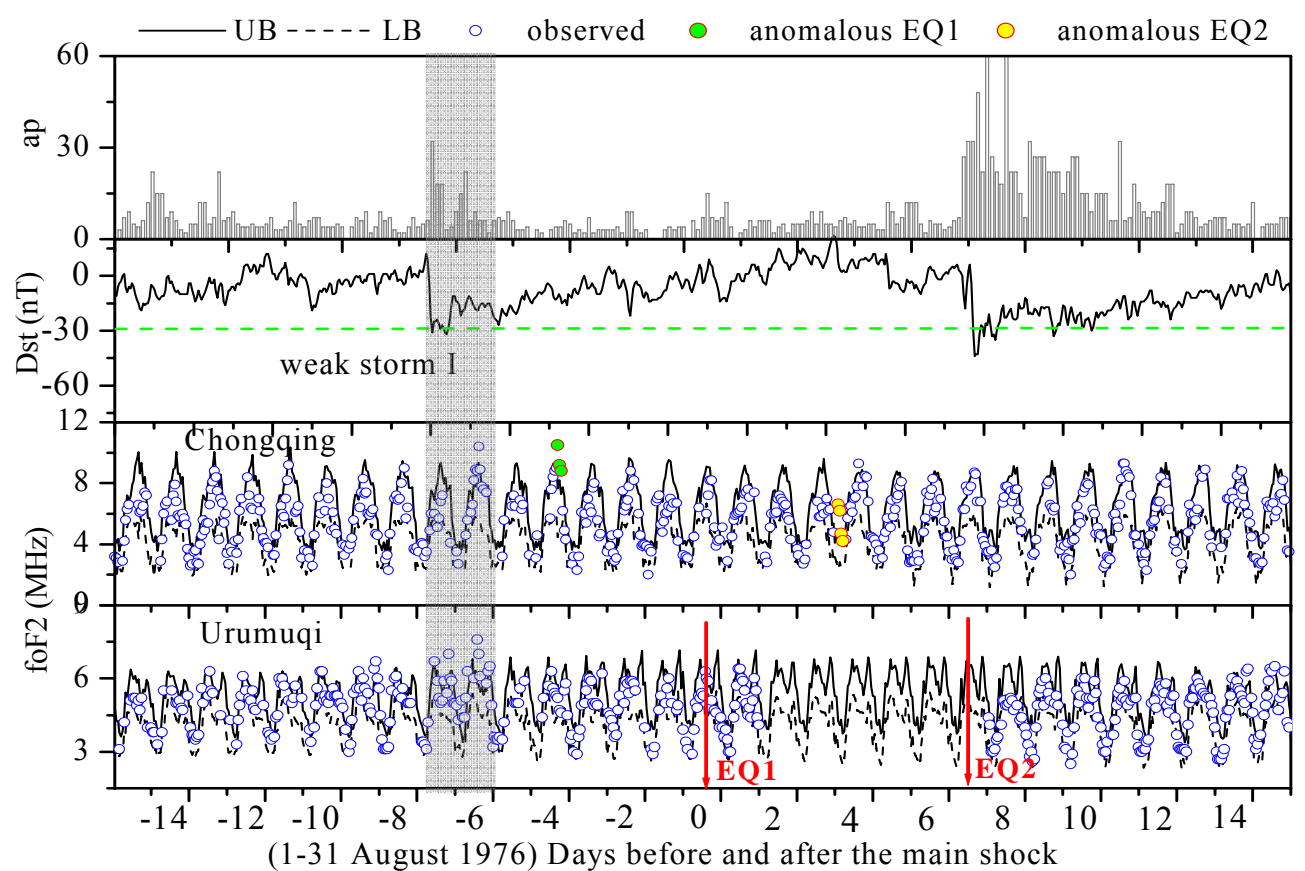

Figure 5. Variations in $f o F 2$ observed by two ground-based stations during 1-31 August 1976. A geomagnetic storm before the shock is marked by the shaded rectangle. The anomalous points related to the Songpan earthquake (16 August 1976, EQ1) are denoted by green circles and those related to the second Songpan earthquake (23 August 1976, EQ2) are denoted by yellow circles.

releasing energy on the surface comparable with that of an M 5.0 earthquake with a depth of $10 \mathrm{~km}$ ) along the Longmenshan fault (Xu et al., 2012b). In addition, there was a storm after the onset of the main shock (day 7), and no distinct disturbances were observed at the two stations. Moreover, ionospheric disturbances lasting for $4 \mathrm{~h}$ related to the Songpan earthquake (23 August 1976) are singled out as well in Fig. 5 (denoted by yellow circles), corresponding to day 3 in Fig. 2. Similarly, there were unobvious disturbances in $f o \mathrm{~F} 2$ over the Urumuqi station.

\section{Local time variation in Q-disturbance events}

Q disturbances are a weakly developed field in ionospheric physics. By excluding the effects from solar and geomagnetic activity, quiet time F2-layer disturbances are assumed to be forced from below, the so-called meteorological control of the ionosphere (Rishbeth, 2006). The perturbations originating from the lower atmosphere are tied to atmospheric waves, including atmospheric tides, planetary waves, and gravity waves (Lastovicka, 2007). A series of publications by Mikhailov et al. $(2004,2007,2009)$ demonstrated that 


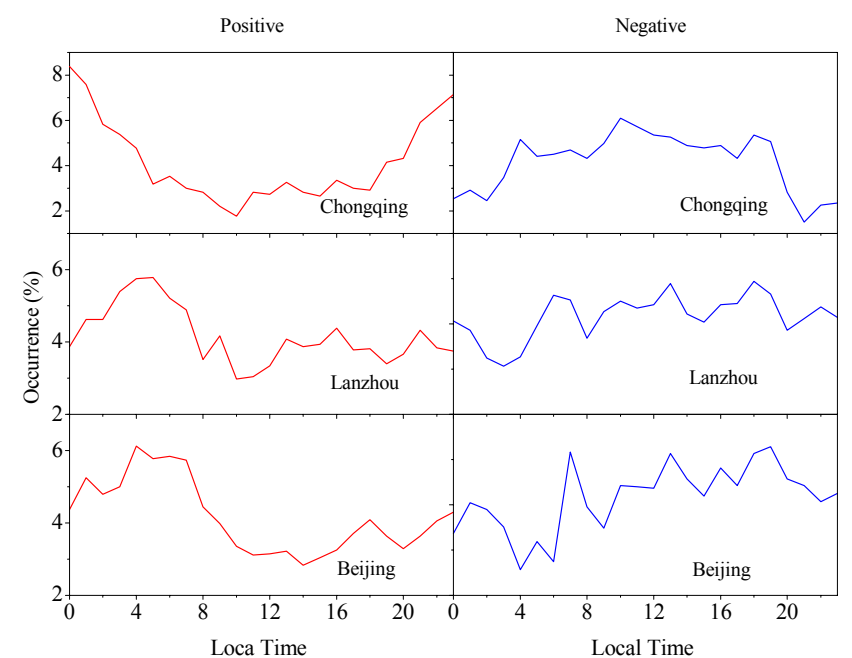

Figure 6. Occurrence of positive and negative Q disturbances versus local time over Chongqing, Lanzhou, and Beijing.

the main morphological features of Q disturbances could be explained within the framework of the contemporary understanding of the thermosphere-ionosphere interaction. However, the morphology and mechanisms of Q disturbances are still far from being well understood.

Ionospheric variation exhibits significant regional (longitudinal or latitudinal) characteristics. To obtain the features of LT variation in Q disturbances in China, hourly values of $f o \mathrm{~F} 2$, routinely scaled from three ionospheric observatories - i.e., Chongqing $\left(29.50^{\circ} \mathrm{N}, 106.40^{\circ} \mathrm{E}\right)$, Lanzhou $\left(36.06^{\circ} \mathrm{N}\right.$, $\left.103.87^{\circ} \mathrm{E}\right)$, and Beijing $\left(40.00^{\circ} \mathrm{N}, 116.30^{\circ} \mathrm{E}\right)$, China, during the interval of 1978-2008 (solar cycle 21, 22, and 23)are analyzed. In order to compare with the features of LT variation before earthquakes, as shown in Fig. 3, the criterion of Liu et al. (2004) was used in the statistical analysis of $\mathrm{Q}$ disturbances. This criterion has been widely used in evaluating variation in F2-layer ionospheric parameters unrelated to earthquakes (Yadav et al., 2010). Q disturbances refer to hourly $f o \mathrm{~F} 2$ deviation from $\mathrm{UB}$ or LB lasting more than $3 \mathrm{~h}$, if $3 \mathrm{~h}$ geomagnetic Ap indices were $\leq 7$ for 24 previous hours. This condition of geomagnetic activity is the same as that proposed by Mikhailov et al. (2004). It should be pointed out that a 27-day running median was used for the day in question instead of a 15-day running median, and deviations in $N m \mathrm{~F} 2$ more than $40 \%$ were referred to as $\mathrm{Q}$ disturbances in Mikhailov et al. (2004). However, the results show that features of LT variation in positive $\mathrm{Q}$ disturbances obtained by the criteria exhibit similar features, while the opposite is true for LT variation in negative $\mathrm{Q}$ disturbances. The behavior according to the different criteria will be discussed in Sect. 4.

Firstly, we check the LT variation in Q disturbances over Chongqing. The Chongqing station is located at the main seismic fault, Longmenshan, in the southwest of China,

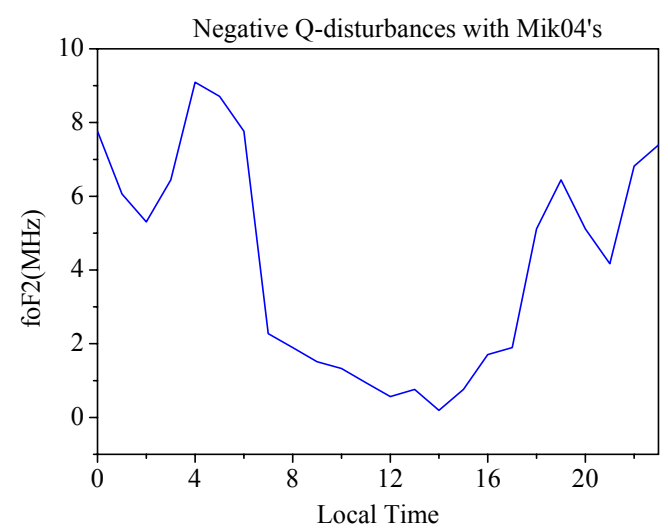

Figure 7. Local time variation in negative $\mathrm{Q}$ disturbances with Mik04's criterion, consistent with the result of Mik04.

where the great Wenchuan earthquake occurred. With more than 3000 Q-disturbance events, the distribution of the occurrence of positive and negative $\mathrm{Q}$ disturbances versus $\mathrm{LT}$ is presented in Fig. 6. A well-pronounced nighttime peak takes place for positive disturbances, which is in agreement with the result achieved by Mikhailov et al. (2004) (from here on referred to as "Mik04"), whereas negative disturbances exhibit a daytime peak. Despite strong fluctuations, compared with the results from Chongqing, similar features of LT variation for positive and negative disturbances over Lanzhou and Beijing are still visible in Fig. 6. As discussed in Sect. 2, the positive disturbances in the ionosphere in the daytime, especially in the afternoon LT sector, are an important feature of ionospheric anomalies related to earthquakes; this is contrary to that of positive $\mathrm{Q}$ disturbances (frequent occurrence at nighttime). This implies that because of their high correlation with earthquakes, much more attention should be paid to positive anomalies in the afternoon LT sector under quiet geomagnetic conditions in China.

\section{Discussion}

It should be stressed that the LT variation in negative $\mathrm{Q}$ disturbances is contrary to that of Mik04, in which the negative and positive disturbances both exhibit similar features, with significant occurrences in the daytime. Figure 7 shows the LT variation in negative disturbances obtained by Mik04's criterion over Chongqing. One can see that the LT variation in negative $\mathrm{Q}$ disturbances over Chongqing is in line with that of Mik04. Hence, the discrepancies are possibly due to the different criteria defining $Q$ disturbances. According to Mik04's criterion, Q disturbances referred to hourly $\left(N m \mathrm{~F} 2 / N m \mathrm{~F} 2{ }_{\text {med }}-1\right)$ deviations of more than $40 \%$. In general, the amplitude of the running $N m \mathrm{~F} 2(f o \mathrm{~F} 2)$ median in the daytime is much bigger than that at nighttime; hence, using this criterion, only the data much lower than the median will be considered as negative disturbances. But the range 


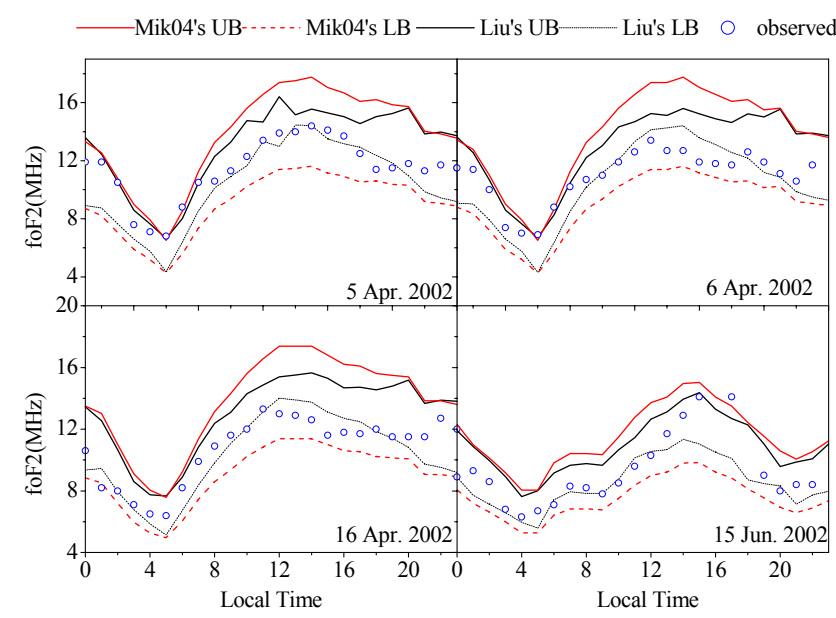

Figure 8. Examples of discrepancy related to negative disturbances defined by two criteria: Liu's and Mik04's. The observed data deviate from the lower bound of Liu's, treated as negative disturbances, but are covered by the range of Mik04's, and treated as normal variation.

of UB and LB, calculated by Liu's method, is mainly determined by the deviation distribution, rather than the running median. For more illustrative interpretation, Fig. 8 displays several examples of negative ionospheric disturbances in $f o \mathrm{~F} 2$ over Chongqing with Liu's criterion. As discussed above, the observed data of $f o \mathrm{~F} 2$ obviously deviated from Liu's lower bound during daytime, but they were covered by Mik04's criterion, and hence were not considered as negative disturbances (did not exceed Mik04's lower bound). However, with the two criteria, we obtain similar features of $\mathrm{LT}$ variation in positive $\mathrm{Q}$ disturbances, which is contrary to those triggered by earthquakes.

How to define the "normal" behavior of the ionosphere treated as a reference value to evaluate ionospheric variation is still an open question. UB and LB can be constructed by different medians. For example, Dabas et al. (2007) and Sharma et al. (2010) used a monthly median instead of a 15day running median to calculate the bounds. But anomalies of $f o \mathrm{~F} 2$ treated as the precursors should be distinct (pronounced decreases or increases); thus the discrepancy of medians should not make a significant contribution to the results. Figure 9 shows ionospheric variation several days before the main shock of the Songpan earthquake (16 August 1976, as shown in Fig. 5), tested by the bounds based on 15day, 27-day, and 30-day running and monthly medians. Despite the different bounds constructed by the corresponding medians, the same abnormal points (during 15:00-17:00 LT), denoted by greeb circles, were singled out. Disturbances related to geomagnetic activity (6 days before the main shock) were also singled out.

However, further investigation, especially validation of the reported ionospheric anomalies before earthquakes, is required in future research. The existence of and temporal vari- ation in ionospheric anomalies before earthquakes are still controversial (Rishbeth, 2006). A number of papers have reported on the ionospheric disturbances before the 2008 Wenchuan earthquake, but why were there no ionospheric anomalies before the $\mathrm{M}=7.02013 \mathrm{Ya}$ 'an earthquake (He et al., 2014), along the same Longmensan fault? Why are there fewer reports on ionospheric anomalies before earthquakes located in high latitudes? And why do the ionospheric anomalies before earthquakes exhibit distinct features of LT variation? In addition, Kon et al. (2011) statistically analyzed TEC anomalies associated with $M \geq 6.0$ earthquakes during the 12-year period of 1998-2010 in Japan, but the results were rebutted by Masci (2012), who attributed these disturbances to geomagnetic activity. Recently, Kamogawa and Kakinami (2013) claimed that the variation in slant TEC from $40 \mathrm{~min}$ before the Tohoku earthquake, reported by Heki (2011), was due to a tsunami rather than a precursory enhancement.

On the other hand, although an improved coupling model for lithosphere-atmosphere-ionosphere coupling was developed by several authors (Sorokin and Hayakawa, 2013; Kuo et al., 2014), the mechanism of the seismo-ionospheric precursor is far from being well understood. There is a tendency of transition from acoustically-driven mechanisms to electric-field coupling (Pulinets and Davidenko, 2014). The seismogenic electric field is postulated due to the emission of radioactive particles (radon) into the atmosphere within the area of the earthquake preparation zone. The anomalous electric field then penetrates into the lower ionosphere and disturbs the ionosphere. Kim et al. (1994) first calculated the electric field in the ionosphere as about $1 \mathrm{mV} \mathrm{m}^{-1}$ in a columnar coordinate, for a given external vertical electric field of $1000 \mathrm{~V} \mathrm{~m}^{-1}$. However, the electric field might be overestimated. In the presence of a normal vertical electric field of $\sim 100 \mathrm{~V} \mathrm{~m}^{-1}$, Ampferer et al. (2010) and Xu et al. (2015) obtained a rather weak electric field of $\sim \mu \mathrm{V} \mathrm{m}^{-1}$ in the ionosphere, due to the low conductivity of the atmospheric layer. To obtain an electric field of $\sim \mathrm{mV} \mathrm{m}^{-1}$ in the ionosphere, the ground vertical electric field should be $10^{5} \mathrm{mV} \mathrm{m}^{-1}$, and such a huge value has not been observed. A typical ionospheric background electric field of $1 \mathrm{mV} \mathrm{m}^{-1}$ dominantly induced by neutral air wind, i.e., $\boldsymbol{E}=U \times \boldsymbol{B}$, will produce a plasma drift velocity of about $40 \mathrm{~m} \mathrm{~s}^{-1}$ in the equatorial ionosphere through the effect of $\boldsymbol{E} \times \boldsymbol{B}$. Hence, the $\sim \mu \mathrm{V} \mathrm{m}^{-1}$ electric field only leads to $\sim 0.04 \mathrm{~m} \mathrm{~s}^{-1}$ drift velocity, which need not be considered in investigating ionospheric variation. Sorokin and Hayakawa (2013) obtained several $\mathrm{mV} \mathrm{m}^{-1}$ electric field in the ionosphere by introducing an external current, $J_{e}$, generated by charged aerosols injected into the atmosphere and keeping the total current divergence-free; $\left(J+J_{e}\right)=0$. However, in a recent paper, Pulinets and Davidenko (2014) doubted the existence of charged aerosols, and proposed the concept of the global electric circuit (GEC), providing a reasonable explanation of the anomalous electric field in the ionosphere, due to the de- 


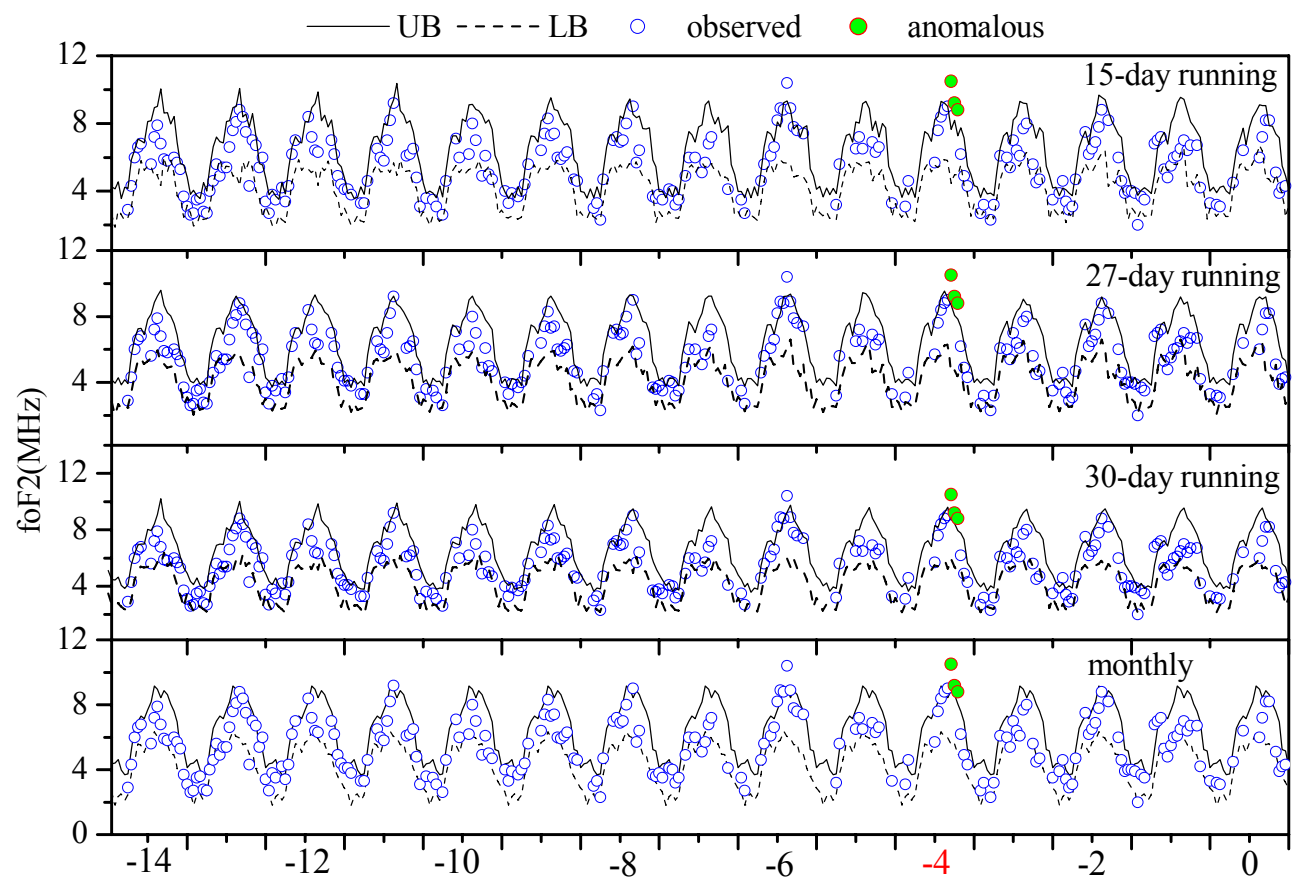

(2-16 Aug. 1976) Days before the main shock

Figure 9. Ionospheric variation several days before the main shock, checked by the bounds based on 15-day, 27-day, and 30-day running and monthly medians. The same anomalous points were singled out.

creasing atmospheric conductivity and the increasing ionospheric potential. In contrast, Omori et al. (2007) argued that the radon emanation increased the number density of small ions and the atmospheric conductivity, consequently decreasing the atmospheric electric field, a view also shared by Harrison et al. (2010).

\section{Conclusions}

The difference of LT variation in $f o \mathrm{~F} 2$ between earthquakeinduced and Q-disturbance events in China was analyzed. The results show that positive disturbances in $f o \mathrm{~F} 2$ due to earthquakes are frequent in the daytime, especially in the afternoon LT sector, but Q disturbances are frequent at nighttime. It is very difficult to obtain a unique feature of ionospheric precursors for the prediction of earthquakes, due to complicated variation in the ionosphere. However, these contrary features (i.e., positive disturbances are frequent in the daytime/nighttime related to earthquakes/Q disturbances) indicate that pronounced enhancement in the F2-layer in the afternoon LT sector under quiet geomagnetic conditions in China is quite possibly due to a forthcoming earthquake. With information of spatial distribution (i.e., the local characteristics limited around the epicenter) of ionospheric anomalies, the $\mathrm{LT}$ variation in $f o \mathrm{~F} 2$ is expected to be a helpful feature in distinguishing seismo-ionospheric precursors. Since the 2008 Wenchuan earthquake, the Chinese government has become more conscious of the importance of ionospheric precursors. A seismo-electromagnetic satellite inspired by the successful application of the DEME-TER satellite ( $\mathrm{Li}$ and Parrot, 2013) is in the process of being constructed, and a high-resolution ionospheric observation network (GBHIO) comprising 5 vertical and 20 oblique sounding stations for seismo-ionospheric monitoring was established in 2009 (Xu et al., 2011b). Combining ground-based observations of ionospheric parameters, seismo-electromagnetic signals, and other phenomena could be helpful in understanding the features and mechanisms of pre-earthquake anomalies in the ionosphere.

Acknowledgements. This work was supported by the National Natural Science Foundation of China (grant no. 41004066), and the Seismic Public Welfare Scientific Research Special Appropriation Project of China (grant no. 201008007). The authors acknowledge the SWDC for the free download of geomagnetic indices.

The topical editor H. Kil thanks K. Ryu and one anonymous referee for help in evaluating this paper.

\section{References}

Ampferer, M., Denisenko, V. V., Hausleitner, W., Krauss, S., Stangl, G., Boudjada, M. Y., and Biernat, H. K.: Decrease of the electric field penetration into the ionosphere due to low conductivity at 
the near ground atmospheric layer, Ann. Geophys., 28, 779-787, doi:10.5194/angeo-28-779-2010, 2010.

Dabas, R. S., Rupesh, M. D., Sharma, K. M., and Pillai, K. G.: Ionospheric per-cursors observed over low latitudes during some of the recent major earthquakes, J. Atmos. Solar-Terr. Phys., 69, 1813-1824, 2007.

Davidenko, D. V.: Diagnostics of ionospheric disturbances over seismo-hazards regions (Ph.D thesis), Fiodorov Institute of Applied Geophysics, Moscow, 2013.

Dobrovolsky, I. R., Zubkov, S. I., and Myachkin, V. I.: Estimation of the size of earthquake preparation zones, Pur. Appl. Geophys., 117, 1025-1044, 1979.

Forbes, J. M., Palo, S., and Zhang, X.: Variation of the ionosphere, J. Atmos. Solar-Terr. Phys., 62, 685-693, 2000.

Harrison, R. G., Aplin, K. L., and Rycroft, M. J.: Atmospheric electricity coupling between earthquake regions and ionosphere, J. Atmos. Solar-Terr. Phys., 72, 376-381, doi:10.1016/j.jastp.2009.12.004, 2010.

He, L. M., Wu, L. X., Pulients, S. A., Liu, S. J., and Yang, F.: A nonlinear background removal method for seismo-ionospheric anomaly analysis under a complex solar activity scenario: A case study of the M9.0 Tohoku earthquake, Adv. Space, Res. 50, 211220, 2012.

He, L. M., Wu, L. X., Santis, A. D, Liu, S. J., and Yong, Y.: Is there a one to one correspondce between ionospheric anomalies and large earthquakes along Longmenshan faults, Ann. Geophys., 32, 187-196, 2014,

http://www.ann-geophys.net/32/187/2014/.

Heki, K.: Ionospheric electron enhancement preceding the 2011 Tohoku-Oki earthquake, Geophys. Res. Lett., 38, L17312, doi:10.1029/2011GL0447908, 2011.

$\mathrm{Hu}$, Y. L.: Primary study on ionospheric precursors of earthquakes with ionospheric data in China (Master thesis), CRIRP, 2011 (in Chinese).

$\mathrm{Hu}$, Y. L., Xu. T., and Wu, J.: Removing solar radiation based on the empirical mode decomposition method for seismo-ionospheric anomaly before the M9.0 Tohoku earthquake, Chin. J. Space Res., 33, 518-524, 2013.

Kamogawa, K. and Kakinami, Y.: Is an ionospheric electron enhancement preceding the 2011 Tohoku-Oki earthquake a precursor?, J. Geophys. Res., 118, 1751-17549, doi:10.1002/jgra50118, 2013.

Kim, V. P., Khegai, V. V., and Illich-Svitych, P. V.: On one possible ionospheric precursor of earthquake, Phys. Solid Earth, 30, 223 226, 1994.

Kon, S., Nishihashi, M., and Hattori, K.: Ionospheric anomalies possibly associated with $M \geq 6.0$ earthquakes in the Japan area during 1998-2010: case studies and statistical study, J. Asian Earth Sci., 41, 410-420, 2011.

Kuo, C. L., Lee, L. C., and Huba, J. D.: An improved coupling model for the lithosphere-atmosphere-ionosphere system, J. Geophys. Res., 119, 3189-3205, doi:10.1002/2013JA019392, 2014.

Lastovicka, J.: Forcing of the ionosphere by waves from below, J. Atmos. Solar-Terr. Phys., 68, 479-497, 2006.

Le, H., Liu, J. Y., and Liu, L.: A statistical analysis of ionospheric anomalies before $736 \mathrm{M} 6.0^{+}$earthquakes during 2002-2010, J. Geophys. Res., 116, A02303, doi:10.1029/2010JA015781, 2011.
Li, M. and Parrot, M.: Statistical analysis of an ionospheric parameter as a base for earthquake prediction, J. Geophys. Res., 118, 3731-3739, doi:10.1002/jgra, 2013.

Liu, J. Y., Chuo, Y. J., Shan, S. J., Tsai, Y. B., Chen, Y. I., Pulinets, S. A., and Yu, S. B.: Pre-earthquake ionospheric anomalies registered by continuous GPS TEC measurements, Ann. Geophys. 22, 1585-1593, doi:10.5194/angeo-22-1585-2004, 2004.

Liu, J. Y., Chen, Y. I., Chuo, Y.J., and Chen, C.S.: A statistical investigation of preearthquake ionospheric anomaly, J. Geophys. Res., 115, A05304, doi:10.1029/2005JA011333, 2006.

Liu, J. Y., Le, H., and Chen, Y. I.: Observations and simulations of seismo-ionospheric GPS total electron content anomalies before the 12 January 2010 M7.0 Haiti earthquake, J. Geophys. Res., 116, A04302, doi:10.1029/ 2010JA015704, 2011.

Masci, F.: The study of ionospheric anomalies in Japan area during 1998-2010 by Kon et al.: An inaccurate claim of earthquakerelated signatures?, J. Asian Eath Sci., 57, 1-5, 2012.

Mikhailov, A. V., Depueva, A. H., and Leschinskaya, T. Y.: Morphology of quiet time F2-layer disturbances: High and lower latitudes, Int. J. Geomag. Aeronom., 5, GI1006, doi:10.1029/2003GI000058, 2004.

Mikhailov, A. V., Depueva, A. H., and Depuev, V. H.: Daytime F2layer negative storm effect: what is the difference between storminduced and Q-disturbance events?, Ann. Geophys., 25, 15311541, 2007, http://www.ann-geophys.net/25/1531/2007/.

Mikhailov, A. V., Depueva, A. H., and Depuev, V. H.: Quiet time F2-layer disturbances: seasonal variation of the occurrence in the daytime sector, Ann. Geophys., 27, 329-337, 2009, http://www.ann-geophys.net/27/329/2009/.

Omori, Y., Yasuoka, Y., Nagahama, H., Kawada, Y., Ishikawa, T., Tokonami, S., and Shinogi, M.: Anomalous radon emanation linked to preseismic electromagnetic phenomena, Nat. Hazards Earth Syst. Sci., 7, 629-635, doi:10.5194/nhess-7-629-2007, 2007.

Perrone, L., Korsunova, L. P., and Mikhailov, A. V.: Ionospheric precursors for crustal earthquakes in Italy, Ann. Geophys., 28, 941-950, doi:10.5194/angeo-28-941-2010, 2010.

Pulinets, S. A., Legen'ka, A. D., and Zelenova, T. I.: Local-time dependence of seismo-ionospheric variations at the F-layer maximum, Geomag. Aeronom., 38, 400-402, 1998a.

Pulinets, S. A.: Seismic activity as a source of the ionospheric variability, Adv. Space Res., 22, 903-906, 1998b.

Pulinets, S. A., Legen'ka, A. D., Gaivoronskaya, T. V., and Depuev, V. K.: Main phenomenological features of ionospheric precursors of strong earthquakes, J. Atmos. Solar-Terr. Phys., 65, 1337 1347, 2003.

Pulinets, S. A. and Tsybulya, K. G.: Unique variation of the total electron content in the preparation period of Haitian earthquake (M7.9) on January 12, 2010, Geomagn. Aeron., 50, 686-689, 2010.

Pulients, S. A. and Davidenko, D.: Ionospheric precursors of earthquakes and Global Electric Circuit, Adv. Space Res., 53, 709723, 2014.

Rishbeth, H.: F-region links with the lower atmosphere?, J. Atmos. Solar-Terr. Phys., 68, 469-478, 2006.

Saradjian, M. R. and Akhoondzadeh, M.: Prediction of the date, magnitude and affected area of impending strong earthquakes using integration of multi precursors earthquake parameters, Nat. 
Hazards Earth Syst. Sci., 11, 1109-1119, doi:10.5194/nhess-111109-2011, 2011.

Sharma, K., Dabas, R. S., Sarkar, S., Das, R. M, Ravindran S., and Gwal, A. K.: Anomalous enhancement of ionospheric F2 layer critical frequency and total electron content over low latitudes before three recent major earthquakes in China, J. Geophys. Res., 115, A11313, doi:10.1029/2009JA014842, 2010.

Sorokin, V. and Hayakawa, M.: Generation of seismic-related DC electric fields and lithosphere-atmosphere- ionosphere coupling, Mod. Appl. Sci., 7, 1-23, 2013.

Xu, T., Hu, Y. L., Wu, J., Wu, Z. S.., Suo, Y. C., Feng, J., and Huang, C. J.: Abnormal perturbations in the ionospheric F2 region before Wenchuan earthquake on 12 May 2008, Sci. China Earth Sci., 53, 1671-1674, 2010a

Xu, T., Hu, Y. L., Wu, J., Wu, Z. S., Suo, Y. C. and Feng, J.: Giant disturbance in the ionospheric $\mathrm{F} 2$ region prior to the M8.0 Wenchuan earthquake on 12 May 2008, Ann. Geophys., 28, 1533-1538, 2010b, http://www.ann-geophys.net/28/1533/2010/.

Xu, T., Hu, Y. L., Wu, J., Wu, Z. S., Li, C. B., Xu, Z. W., and Suo, Y.C.: Anomalous enhancement of electric field derived from ionosonde data before the great Wenchuan earthquake, Adv. Space Res., 47, 1001-1005, 2011a.

Xu, T., Wu, J., Zhao, Z., Liu, Y., He, S., Li, J., Wu, Z., and Hu, Y.: Brief communication "Monitoring ionospheric variations before earthquakes using the vertical and oblique sounding network over China", Nat. Hazards Earth Syst. Sci., 11, 1083-1089, doi:10.5194/nhess-11-1083-2011, 2011 b.

Xu, T., Hu, Y. L., Wu, J., Li, C. B., Wu, Z. S., Suo, Y. C., and Feng, J.: Statistical analysis of seismo-ionospheric perturbation associated with $14 \mathrm{Ms} \geq 7.0$ earthquakes in Chinese Mainland, Chin. Radio Sci., 27, 507-512, 2012a (in Chinese).
Xu, T., Hu, Y. L., Zhang, H. L.,Chen, Z., Wu, J., and Xu, Z. W.: Ionospheric disturbances on 8 September, 2010: was it connected with the incoming moderated Chongqing earthquake?, Adv. Space Res., 50, 205-210, 2012b.

$\mathrm{Xu}$, T., Zhang, H. L., Hu, Y. L., and Wu, J..: Electric field penetration into the ionosphere in the presence of anomalous radon emanation, Adv. Space Res., 55, 2883-2888, doi:10.1016/j.asr.2015.03.015, 2015.

Yadav, S., Dabas, R. S., Das, R. M., Upadhayaya, A. K., Sharma, K., and Gwal, A. K.: Diurnal and seasonal variation of F2-layer ionospheric parameters at equatorial ionization anomaly crest region and their comparison with IRI-2001, Adv. Space Res., 45, 361-367, 2010.

Zakharenkova, I. E., Krankowski, A., and Shagimuratov, I. I.: Modification of the low-latitude ionosphere before the 26 December 2004 Indonesian earthquake, Nat. Hazards Earth Syst. Sci., 6, 817-823, doi:10.5194/nhess-6-817-2006, 2006.

Zhao, B. Q., Wang, M., Yu, T., Wan, W. X., Lei, J. H., Liu, L. B., and Ning B. Q.: Is an unusual large enhancement of ionospheric electron density linked with the great Wenchuan earthquake?, J. Geophys. Res., 113, doi:10.1029/2008JA013613, 2008.

Zhou, Y. Y, Wu, Y., and Qiao, X. J.: Ionospheric anomalies detected by ground-based GPS before Mw7.9 Wenchuan earthquake of May 12, 2008, China, J. Atmos. Solar-Terr. Phys., 71, 959-966, 2009. 